\title{
PROYEKSI MANFAAT EKONOMI DARI PENERAPAN STANDAR NASIONAL INDONESIA (SNI) DENGAN MENGGUNAKAN METODOLOGI ISO PADA UMKM GARAM
}

\section{Projection of Economic Benefits From the Implementation of Indonesian National Standard (SNI) Using ISO Methodology on UMKM of Salt}

\author{
Kevin Natanael Nainggolan, Bambang Purwanggono \\ Departemen Teknik Industri, Fakultas Teknik, Universitas Diponegoro, \\ JI. Prof. Soedarto, SH, Kampus Undip Tembalang, Semarang, Indonesia 50275 \\ Email: nainggolankevin97@gmail.com
}

\begin{abstract}
Abstrak
Standarisasi di dunia mulai mengarah pada bagaimana standar mampu memberikan kontribusi terhadap perekonomian suatu negara secara merata. Pada tingkatUMKM standar mempunyai peranan penting dalam pertumbuhan ekonomi, penyerapan tenaga kerja, dan pendistribusian hasil-hasil pembangunan. Hal ini diperkuat dengan beberapa penelitian yang menyatakan bahwa standar dapat memberikan manfaat ekonomi secara nyata. Namun, dilihat dari perspektif pelaku usaha, standar masih dianggap sebagai cost driverdikarenakan mereka menganggap bahwa standar hanya merupakan beban biaya semata dan perusahaan belum mendapatkan hasil dari standar yang telah diterapkan, bahkan belum memberikan manfaat ekonomi terhadap keuntungan mereka. Tujuan penelitian ini adalah untuk mengetahui manfaat ekonomi penerapan standar pada UMKM Garam yang telah SNI (UD. X dan UD. Y) kemudian hasilnya akan menjadi proyeksi UMKM yang sedang menerapkan SNI (UD. A dan UD. B).Tahapan dalam Metodologi ISO meliputi: understand the value chain, analyze value drivers, identify impact of standards, dan asses and consolidate result. Penerapan standarmemberikan manfaat ekonomi, sebesar pada studi kasus di UD X mendapatkan keuntungan ekonomi sebesar Rp. 36.608.907,00 per tahun, UD Y sebesar Rp. 34.808.907,00 per tahun.
\end{abstract}

Kata Kunci: standarisasi, metodologi ISO, UMKM.

\begin{abstract}
Standardization in the world began to lead to the standards given to the European Union. At the standard UMKM level, it has an important role in economic growth, strengthening the workforce, and distributing development results. This is supported by several studies which state that standards can provide tangible economic benefits. However, from a business perspective, standards are still considered cost drivers, and have not even provided economic benefits to their profits. The purpose of this study is to study the benefits of implementing standard economics at Salt UMKM that have SNI then will become projections of UMKM that are implementing SNI. Stages in the ISO Methodology involve: understanding the value chain, analyzing the drivers of value, identifying the impact of standards, and assessing and consolidating results. Application of the standard provides economic benefits, as much as a case study at UD X earns an economic benefit of Rp. 36,608,907.00 per year, UD Y Rp. 34,808,907.00 per year.
\end{abstract}

Keywords : standardization, ISO methodology, UMKM. 


\section{PENDAHULUAN}

Kebutuhan garam yang tinggi ini diharapkan dapat dipenuhi oleh produsen nasional, sehingga penerapan SNI Garam Bahan Baku dan Garam Olahan diharapkan dapat meningkatkan daya saing industri garam dalam negeri serta memperkuat perekonomian nasional.

Pada saat ini, standarisasi di dunia mulai mengarah pada bagaimana standar mampu memberikan kontribusi terhadap perekonomian suatu negara secara merata. Pada level makroekonomi penelitian dilakukan oleh BSN (Badan Standarisasi Nasional) pada tahun 2014 melibatkan produk yang telah ber-SNI (Standar Nasional Indonesia) Hasil penelitian Penelitian yang dilakukan oleh para peneliti standardisasi BSN dilakukan terhadap 5 produk yakni Air Minum Dalam Kemasan (AMDK), Garam Konsumsi Beryodium, Minyak Goreng, Pupuk SP 36, serta Pupuk KCL. Sebagaimana disampaikan oleh Peneliti Muda BSN, Biatna Dulbert (2014), total dampak ekonomi dari produk AMDK bisa mencapai $\mathrm{Rp} 2,78$ milyar. Sedangkan produk minyak goreng mencapai $\mathrm{Rp}$ 17,5 milyar. Garam Konsumsi Beryodium mencapai Rp 399.3 juta. Serta Pupuk KCL dan Pupuk SP 36 masing-masing Rp 0.84 milyar dan Rp 77,3 juta. Angka ini bisa meningkat bila semakin banyak pula industri yang menerapkan SNI.

Penerapan standar memberikan manfaat positif bagi UMKM. Sepuluh UMKM dari sepuluh negara di dunia memberikan kesaksiannya bagaimana standar ISO memberikan kontribusi yang baik, diantaranya membantu berkompetisi dengan perusahaan yang lebih besar, membantu dalam akses pasar ekspor, membantu memberikan praktik bisnis terbaik dan membantu operasi perusahaan menjadi lebih efisien dan berkembang (International Organization for Standardization, 2014). Manfaat ekonomi penerapan standar yang diperoleh oleh UMKM tersebut, banyak yang bersifat intangible dan bersifat makro.

Pada tahun 2010, International Organization for Standardization (ISO) telah mengembangkan suatu metode untuk menghitung manfaat ekonomi dari penerapan standar, metode ini disebut dengan Economic Benefit Standard - ISO Metodologi. Secara umum, metodologi ISO mendorong para peneliti untuk menentukan faktor apa saja yang menjadi value chain dan value driver dalam suatu organisasi yang nantinya akan memberikan manfaat terkait penerapan standar. Value chain merupakan aktivitas yang berhubungan dengan output tertentu, produk atau jasa yang dihasilkan, sedangkan value driver adalah kemampuan penting dari suatu organisasi bisnis yang dapat memberikan keuntungan kompetitif terhadap organisasi tersebut(ISO, 2013).

UD. A dan UD. B adalah Industri Kecil Menengah yang terletak di Kecamatan Wedarijaksa, Kabupaten Pati. UD B dan UD. A pada saat ini sedang melakukan bimbingan untuk penerapan SNI pada produksi garam berjenis garam Briket yang ditangani oleh Global Konsultan dari Kementerian Perindustrian. Kedua UMKM ini yakin dengan diraihnya standar SNI akan mampu menaikkan standar produksi, penjualan, serta pengakuan yang lebih baik dari para pesaingnya.

UD. Y dan UD. $X$ adalah Industri Kecil Menengah juga terletak di Kecamatan Wedarijaksa, Kabupaten Pati. Kedua UMKM ini telah menerapkan SNI pada produk garam sejak tahun 2018. Alasan dipilih nya objek penelitian adalah meskipun telah menerapkan SNI maupun yang sedang menerapkan SNI namun keempat UMKM ini belum pernah mengetahui dan mengukur manfaat penerapan SNI yang telah digunakan melainkan hanya menggunakan SNI namun belum meneliti berapa manfaat yang diberikan oleh standar yang digunakan tersebut. Berdasarkan hasil penelitian menggunakan ISO metodologi, penerapan standar memberikan suatu manfaat ekonomi pada pihak penerap standar (Farkah, 2011; Mulyono \& Pudjiastuti, 2013; Sari, 2012; Ulkhaq, 2010). Penerapan Economic Benefit Standard ISO Metodology dalam menghitung manfaat ekonomi penerapan standar banyak diaplikasikan pada industri skala menengah dan besar. Berkaitan dengan hal tersebut, maka tujuan penelitian ini diharapkan dapat mengetahui manfaat ekonomi pada UMKM yang telah menerapkan SNI kemudian akan digunakan menjadi proyeksi pada UMKM yang sedang menerapkan SNI menggunakan Economic Benefit Standard - ISO Metodology. 


\section{Tinjauan Pustaka}

\subsection{Standar}

Standar adalah spesifikasi teknis atau sesuatu yang dibakukan termasuk tata cara dan metode yang disusun berdasarkan consensus semua pihak yang terkait dengan memperhatikan syarat-syarat keselamatan, keamanan, kesehatan, lingkungan hidup, perkembangan ilmu pengetahuan dan teknologi, serta pengalaman, perkembangan masa kini dan masa yang akan datang untuk memperoleh manfaat yang sebesar-besarnya (Peraturan Pemerintah, 2000).

\subsection{Penerapan SNI}

Penerapan standar adalah kegiatan menggunakan standar sebagai acuan (spesifikasi teknis, aturan, pedoman) untuk suatu kegiatan atau hasilnya, yang pada dasarnya bersifat voluntari (voluntary). Bila suatu standar terkait dengan kesehatan, keamanan, keselamatan, kepentingan perkembangan ekonomi nasional dan kelestarian fungsi lingkungan hidup maka standar dapat diacu dalam suatu regulasi teknis yang selanjutnya pemenuhannya bersifat wajib (mandatory).

\section{$2.3 \quad$ Metodologi ISO}

Sejak 2010, Metodologi ISO telah dikembangkan dalam menghitung manfaat ekonomi dari standar dengan pilot project di beberapa negara berkembang termasuk Indonesia. Metodologi ISO menyediakan kriteria kerangka konsisten, petunjuk dan alat untuk menilai keuntungan ekonomi standar dari perspektif organisasi individual yaitu perusahaan yang berorientasi mencari keuntungan atau perusahaan publik. Penerapan Metodologi ISO ini dapat membantu perusahaan mengetahui lebih baik aktivitas dan proses organisasi yang berhubungan dengan penggunaan standar dengan gambaran peningkatan kinerja dan memaksimalkan keuntungan yang dihasilkannya (Mulyono \& Pudjiastuti, 2013).

Sejak tahun 2010, ISO methodology telah dikembangkan untuk menghitung manfaat ekonomi dari standar dengan pilot project di beberapa negara berkembang, termasuk Indonesia. ISO methodology ditujukan untuk menjawab pertanyaan dasar: Terdapat empat langkah digunakan untuk menilai dampak standar terhadap sebuah organisasi, yakni (ISO,2013) :
1. Menentukan Value Chain

Langkah pertama adalah menentukan Value chain suatu industri (minimal pada level umum) untuk menempatkan perusahaan dalam konteks Value chain industri. Kedua, internalvalue chain perusahaan, hal ini sangat penting untuk memahami proses bisnis perusahaan, organisasinya, dan aktivitasaktivitas nilai tambah perusahaan.

Dalam manajemen bisnis, model ini sebagai alat strategis untuk menganalisa suatu organisasi, yang mempresentasikan seluruh aktivitas perusahaan secara sistematis sebagaimana ditunjukkan pada Gambar 1.

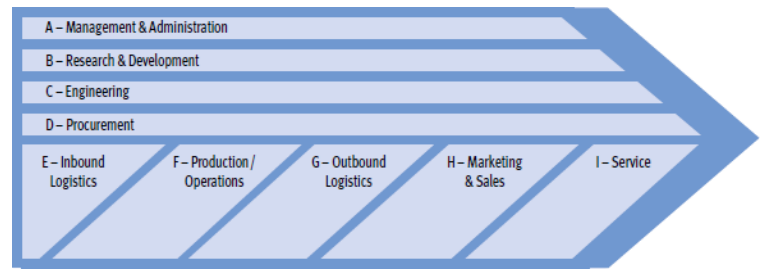

Gambar 1 Value Chain Perusahaan

Gambar diatas menunjukkan value chain perusahaan metodologi ISO Huruf A, B, C, dan $D$ menunjukkan aktivitas sekunder dalam melakukan operasinya agar berjalan lebih baik (Porter, 1985). Huruf E-I menunjukkan aktivitas primer yaitu aktivitas yang terlibat secara langsung dalam penciptaan produk secara fisik, penjualan, dan penyampaian pada pembeli yang termasuk purna jualnya (Porter, 1985)

2. Identifikasi Dampak dari Standar

Pada langkah kedua ini, fungsi dan aktivitas bisnis dalam rantai nilai perusahaan di mana standar diharapkan untuk peran penting. Dokumentasi perusahaan yang ada, mis. manual kualitas, proses dan bagan organisasi, dokumentasi perusahaan atau departemen lainnya, harus digunakan untuk memahami proses, fungsi bisnis dan kegiatan utama yang dilakukan oleh fungsi bisnis yang relevan.

\section{Analisis Value Driver}

Langkah ini dibagi menjadi dua sublangkah berikut: a) analisis driver nilai perusahaan dan b) penentuan operasional indikator yang relevan dengan fungsi bisnis yang dipilih. Value Drivers adalah kemampuan yang sangat penting bagi organisasi yang memberi perusahaan keunggulan kompetitif. Indikator operasional adalah variabel terukur dari aktivitas perusahaan yang menunjukkan peningkatan atau penurunan kinerja.

4. Penilaian dan Konsolidasi Hasil 
Langkah terakhir dalam metodologi ISO adalah mengukur dampak penerapan SNI yang diterapkan oleh UD. Y dan UD. X terhadap produk Garam. Terdapat dua langkah: assess the impacts dan consolidate the result. Hal yang diukur dalam hal ini adalah estimasi keuntungan ekonomi terhadap fungsi bisnis, value drivers, dampak dan indikator operasional per tahun. Setelah didapat hasil manfaat per tahun dalam satuan rupiah selanjutnya hasil tersebut dijumlahkan secara keseluruhan. Kemudian hasil yang diperoleh diharapkan dapat menjadi proyeksi estimasi penggunaan standar pada UD. A dan UD. B.

\section{METODE PENELITIAN}

Metode yang digunakan dalam penelitian ini adalah Economic Benefit Standard - ISO Metodology dan Studi kasusdilakukan pada keempat UMKM garam dimana dua diantaranya sudah menerapkan SNI sedangkan yang lainnya masih dalam proses penerapan. Sebelum melakukan pemecahan masalah penelitian metode penelitian harus dilakukan terlebih dahulu agar penelitian lebih terarah, terencana, sistematis dan memudahkan masalah yang ada. Data manfaat ekonomi penerapan standar diperoleh dari proses wawancara dengan para ahli (supervisor) pada tiap-tiap fungsi bisnis dan pemilik (owner) UMKM. Wawancara dan observasi dimulai pada bulan april 2019. Pengolahan data bertujuan untuk mendapatkan nilai kuantitatif dari keuntungan penerapan standar yang dilakukan pada tiap-tiap fungsi bisnis dalam perusahaan. Hal ini dilakukan dengan membandingkan keadaan sebelum dan sesudah penerapan standar. Setelah dilakukan perhitungan pada masing-masing fungsi bisnis maka hasil perhitungan total pada masingmasing fungsi bisnis dijumlahkan, sehingga didapatkan nilai keuntungan ekonomi total akibat adanya penerapan standar. Penerapan standar dalam penelitian ini adalah SNI ISO 9001:2015 (Sistem Manajemen Mutu), SNI 3556:2010 (Garam Beryodium). Potensi manfaat keuntungan dan estimasi keuntungan ekonomi (nominal) yang diperoleh merupakan justifikasi dari narasumber yang merupakan para ahli dari perusahaan yang menjadi unit analisis.

\section{Hasil dan Pembahasan}

\subsection{Value Chain perusahaan}

Berdasarkan hasil analisis melalui studi pustaka dan wawancara dengan pemilik perusahaan pada UMKM Garam UD Y, UD. X, UD. A, dan UD. B, diketahui potensi keuntungan ekonomi penerapan standar sebagaimana disajikan pada Gambar 2 sebagai berikut:

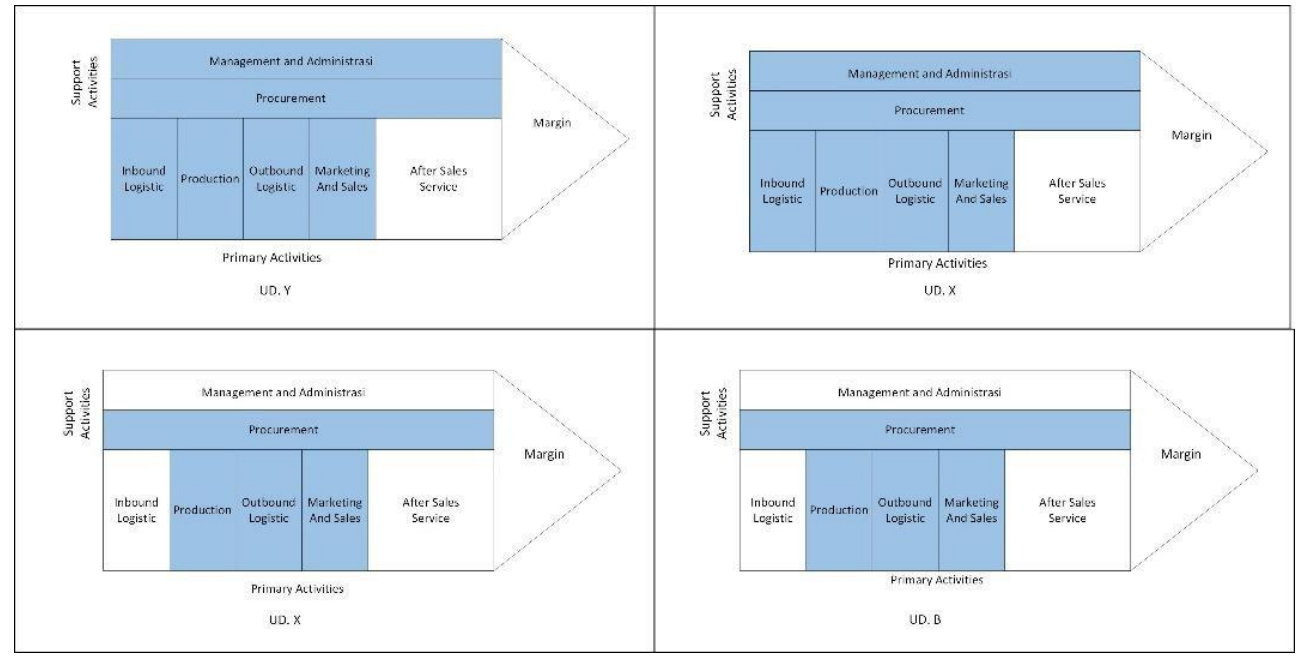

Gambar 2. Rantai Nilai UD. Y, UD X, UD A dan UD. B

Berdasarkan hasil analisa penelitian dan wawancara dengan pemilik UD. Y, UD $X$, diketahui bahwa potensi keuntungan ekonomi karena penerapan standar terdapat fungsi bisnis management and administration, procurement, inbound logistic, production, outbound logistic dan marketing and sales. Potensi keuntungan ekonomi pada UD A dan UD. B memiliki sedikit 
perbedaan dengan yang telah menerapkan standar dikarenakan masih dalam proses penerapan standar diantaranya terdapat fungsi bisnis pengadaan, produksi, logistic outbond, dan penjualan dan pemasaran.

\subsection{Value Drivers dan Indikator Operasional UD. Y dan UD. $X$ \\ Value Drivers adalah kemampuan penting dari suatu organisasi bisnis yang dapat memberikan keuntungan kompetitif terhadap organisasi tersebut (ISO,2010). Dampak penerapan standar dalam suatu proses operasi}

produksi dapat dinilai melalui value driver tersebut.

Setelah value driver dianalisis, selanjutnya menentukan indikator operasional yang relevan dengan fungsi bisnis terpilih. Indikator operasional berfungsi sebagai variabel terukur untuk menilai manfaat standar yang digunakan. Berdasarkan ISO Metodology toolbox penelitian manfaat ekonomi penerapan standar oleh ISO tahun 2013 dan diproyeksikan dengan UD. Ydan UD. $\mathrm{X}$ didapatkan value drivers dan indikator operasional :

Tabel 1 Value Drivers dan Indikator operasional

\begin{tabular}{|c|c|c|c|c|}
\hline No & Value Drivers & Penjelasan & $\begin{array}{c}\text { Indikator } \\
\text { Operasional }\end{array}$ & Fungsi Bisnis \\
\hline 1 & Kualitas produk & $\begin{array}{c}\text { Kemampuan } \\
\text { membuat produk } \\
\text { berkualitas tinggi }\end{array}$ & Penjualan per tahun & $\begin{array}{c}\text { Pemasaran dan } \\
\text { penjualan }\end{array}$ \\
\cline { 4 - 5 } & Efidak Sesuai & \multirow{2}{*}{ produksi } \\
\hline 2 & Produksi & $\begin{array}{c}\text { Kemampuan } \\
\text { mengoptimalkan } \\
\text { waktu proses } \\
\text { produksi }\end{array}$ & Waktu Produksi & \\
\hline
\end{tabular}

\subsection{Keterkaitan Manfaat Penerapan SNI di UD. Y dan UD. $X$}

manajemen. Penggunaan standar yang telah Standar eksternal yang digunakan UD. Y dan UD. X secara umum dapat dibagi menjadi (1) Standar produk, dan (2) Standar untuk proses diidentifikasi dalam fungsi bisnis yang dipilih dan hubungannya dalam mendukung value driver perusahaan dijelaskan secara lebih rinci pada gambar berikut ini.

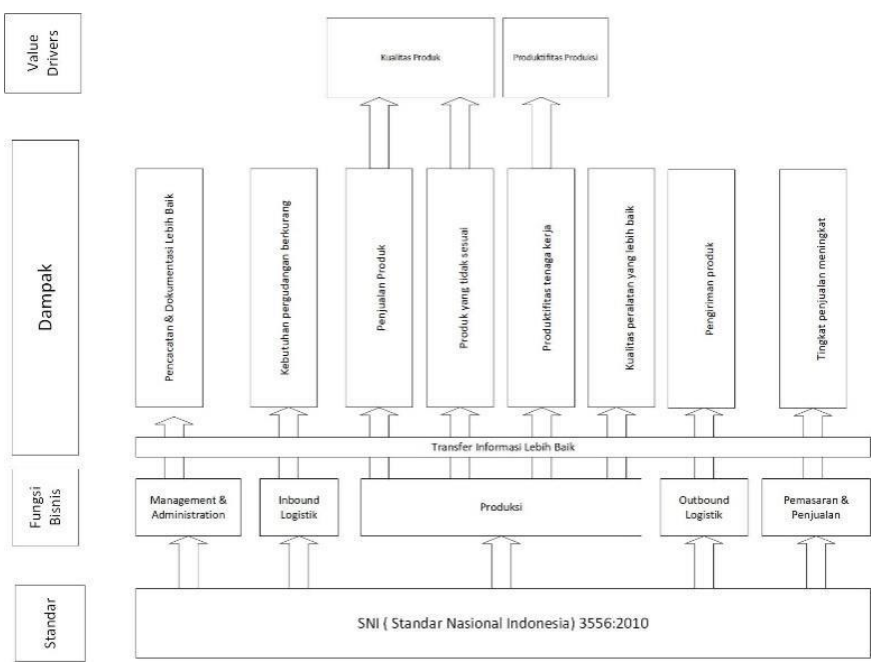

Gambar 3 Keterkaitan standar, fungsi bisnis, dampak, dan value driver UD. X dan UD. Y

\subsection{Menilai dan Menghitung Manfaat} Penerapan SNI UD. Y dan UD. X.

Langkah ini dibagi menjadi dua tahap yaitu manfaat penerapan standar yang dikelompokkan menjadidua, yaitu manfaat kualitatif dan manfaat kuantitatif. Manfaat kuantitatif standar bisa diukur kontibusinya terhadap objek penelitian. 
Tabel 2 Perhitungan keuntungan ekonomi penerapan standar UD X

\begin{tabular}{|c|c|c|c|}
\hline No & Bagian & Potensi Benefit & $\begin{array}{l}\text { Estimasi } \\
\text { Keuntungan } \\
\text { Ekonomi } \\
\text { (Rp/Tahun) }\end{array}$ \\
\hline 1 & $\begin{array}{l}\text { Manajemen dan } \\
\text { administrasi }\end{array}$ & $\begin{array}{l}\text { Adanya pencatatan dokumen mengenai aktivitas } \\
\text { perusahaan }\end{array}$ & Intangible \\
\hline 2 & Logistik Inbond & $\begin{array}{l}\text { Adanya perputaran bahan baku dan produk yang } \\
\text { lebih cepat dan lebih teratur, }\end{array}$ & Intangible \\
\hline 3 & Produksi & $\begin{array}{l}\text { Adanya penurunan produksi yang tidak sesuai } \\
\text { setelah melakukan penerapan SNI dimana sudah } \\
\text { adanya SOP di tiap masing masing proses } \\
\text { pengerjaan yang membuat mengerti bagaimana } \\
\text { pengerjaan produk yang baik. }\end{array}$ & Rp7.693.735,00 \\
\hline 4 & Pembakaran Garam & $\begin{array}{l}\text { - Sebelum SNI : proses oven dilakukan selama } \\
\pm 1,2 \text { jam dikarenakan belum adanya standar ditiap } \\
\text { proses baik proses oven maupun sebelum proses } \\
\text { oven yang menyebabkan memakan waktu yang } \\
\text { lama. } \\
\text { - Setelah SNI : setiap proses sudah terstandar } \\
\text { dengan baik dan mengikuti aturan standar } \\
\text { menyebabkan proses oven dapat berlangsung } \\
\text { lebih cepat dari sebelumnya menjadi } \pm 50 \text { menit. }\end{array}$ & Rp29.040.000,00 \\
\hline 5 & Pemasaran & $\begin{array}{l}\text { tal produk garam yang terjual pada tahun } 2016 \\
\text { sebanyak } 303780 \mathrm{Kg} \text { dengan rata-rata penjualan } \\
\text { per bulan ialah sebesar } 25315 \mathrm{Kg} \text {. kemudian, } \\
\text { terjadi peningkatan sebesar } 1,5 \% \text { dari setelah } \\
\text { UD. X menerapkan standar. }\end{array}$ & Rp11.388.135,00 \\
\hline 6 & Pemasaran & $\begin{array}{l}\text { Pendorong keunggulan UD. X adalah hasil dari } \\
\text { kontribusi beberapa faktor utama, yaitu: sertifikat } \\
\text { SNI, peralatan produksi yang mendukung dan } \\
\text { produk yang memenuhi spesifikasi standar. }\end{array}$ & Intangible \\
\hline 7 & Pengiriman & $\begin{array}{l}\text { adanya penjaminan pengiriman dalam kondisi } \\
\text { aman dan menggunakan transportasi yang layak } \\
\text { pakai, }\end{array}$ & Intangible \\
\hline 8 & Penanganan Limbah & $\begin{array}{l}\text { Garam yang tidak sesuai atau cacat akan dijual } \\
\text { kembali sebagai untuk keperluan telur asin dan } \\
\text { lain lain. }\end{array}$ & Rp304.500,00 \\
\hline
\end{tabular}

Tabel 2 Perhitungan keuntungan ekonomi penerapan standar UD Y

\begin{tabular}{|c|c|c|c|}
\hline No & Bagian & Potensi Keuntungan & $\begin{array}{l}\text { Estimasi } \\
\text { Keuntungan } \\
\text { Ekonomi } \\
\text { (Rp/Tahun) }\end{array}$ \\
\hline 1 & $\begin{array}{l}\text { Manajemen dan } \\
\text { administrasi }\end{array}$ & 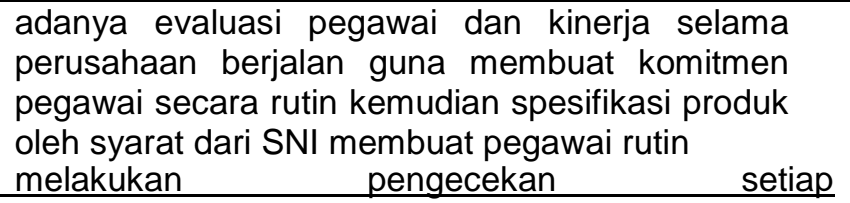 & Intangible \\
\hline
\end{tabular}




\begin{tabular}{|c|c|c|c|}
\hline 2 & $\begin{array}{l}\text { Manajemen dan } \\
\text { administrasi }\end{array}$ & $\begin{array}{l}\text { Adanya pencatatan dokumen mengenai aktivitas } \\
\text { apa saja yang telah dilakukan perusahaan selama } \\
\text { proses pengerjaan berlangsung }\end{array}$ & Intangible \\
\hline 3 & Pengadaan & $\begin{array}{l}\text { adanya pemilihan supplier dan penjamin bahan } \\
\text { baku dalam kualitas yang baik, monitoring bahan } \\
\text { baku yaitu Garam Krosok dan Yodium. }\end{array}$ & Intangible \\
\hline 4 & Logistik Inbond & $\begin{array}{l}\text { Adanya perputaran bahan baku dan produk yang } \\
\text { lebih cepat dan lebih teratur, sehingga bahan baku } \\
\text { dan produk jadi memerlukan waktu yang lebih } \\
\text { sedikit untuk disimpan digudang dan adanya } \\
\text { perbaikan kapasitas gunang yang lebih besar dan } \\
\text { lebih rapi }\end{array}$ & Intangible \\
\hline 5 & Produksi & $\begin{array}{l}\text { Adanya penurunan produksi yang tidak sesuai } \\
\text { setelah melakukan penerapan SNI dimana sudah } \\
\text { adanya SOP di tiap masing masing proses } \\
\text { pengerjaan yang membuat mengerti bagaimana } \\
\text { pengerjaan produk yang baik. }\end{array}$ & Rp7.188.826,00 \\
\hline 6 & Pembakaran Garam & $\begin{array}{l}\text { Dengan melakukan penerapan SNI, dalam rangka } \\
\text { memenuhi permintaan pelanggan yang cenderung } \\
\text { meningkat, pihak perusahaan perlu melakukan } \\
\text { efisiensi waktu produksi untuk meningkatkan } \\
\text { jumlah produksi tanpa melakukan penambahan } \\
\text { jumlah shift atau waktu pengerjaan. Maka, } \\
\text { perubahan yang dilakukan adalah: } \\
\text { - sebelum SNI : SNI proses oven dilakukan selama } \\
1,3 \text { jam dikarenakan belum adanya standar ditiap } \\
\text { proses baik proses oven maupun sebelum proses } \\
\text { oven yang menyebabkan memakan waktu yang } \\
\text { lama } \\
\text { - Setelah SNI : setiap proses sudah terstandar } \\
\text { dengan baik dan mengikuti aturan standar } \\
\text { menyebabkan proses oven dapat berlangsung } \\
\text { lebih cepat dari sebelumnya menjadi } 55 \text { menit } \\
\text { Dengan demikian, benefit yang didapatkan yaitu } \\
\text { waktu produksi. }\end{array}$ & Rp 12.759.600,00 \\
\hline 6 & Pemasaran & $\begin{array}{l}\text { telah menerapkan SNI pada produk garam, terapat } \\
\text { nya peningkatan penjualan. Peningkatan } \\
\text { penjualan sebesar } 1,89 \% \text { setelah penerapan SNI. }\end{array}$ & Rp14.160.481,00 \\
\hline & & $\begin{array}{l}\text { Pendorong keunggulan Karya Jaya adalah hasil } \\
\text { dari kontribusi beberapa faktor utama, yaitu: } \\
\text { sertifikat SNI, dan produk yang memenuhi } \\
\text { spesifikasi standar. faktor ini berjalan beriringan, } \\
\text { terbukti dengan adanya peningkatan penjualan } \\
\text { akibat penerapan SNI. }\end{array}$ & \\
\hline 7 & Pemasaran & $\begin{array}{l}\text { Sertifikasi memberikan kemudahan perusahaan } \\
\text { dalam meraih kepercayaan pelanggan. Manfaat } \\
\text { lainnya ialah area pemasaran yang bertambah } \\
\text { luas dimana pada awal berdirinya perusahaan } \\
\text { pemasaran hanya terdapat dilakukan didaerah pati } \\
\text { kemudian setelah penerapan SNI terjadi } \\
\text { pemasaran dan penjualan produk pun meningkat } \\
\text { sampai ke daerah JABODETABEK. }\end{array}$ & Intangible \\
\hline 8 & Pengiriman & $\begin{array}{l}\text { adanya penjaminan pengiriman dalam kondisi } \\
\text { aman dan menggunakan transportasi yang layak }\end{array}$ & Intangible \\
\hline
\end{tabular}




\begin{tabular}{ccc}
\hline \multicolumn{3}{c}{ pakai, baik pengiriman dalam maupun luar kota, } \\
kondisi packing yang rapi dan sesuai dengan SOP \\
\hline \\
$\begin{array}{l}\text { Garam yang tidak sesuai atau cacat akan dijual } \\
\text { kembali sebagai untuk keperluan telur asin dan lain }\end{array}$ \\
\hline Penanganan Limbah \\
$\begin{array}{l}\text { lain. Sehingaa tidak ada produk yang terbuang dan } \\
\text { dapat mengurangi limbah perusahaan. (limbah } \\
\text { tersebut diambil langsung oleh pembeli). }\end{array}$ & Rp. 272.000,00 \\
\hline Total manfaat ekonomi penerapan standar & Rp34.302.107,00
\end{tabular}

\section{UCAPAN TERIMA KASIH}

\section{KESIMPULAN}

Hal - Hal yang dapat disimpulkan dari hasil penelitian ini adalah sebagai berikut:

1. Pada UD. Y dan UD Xmemiliki fungsi bisnis manajemen dan administrasi, pengadaan,Logistik inbond, produksi, logistic outbond sertapenjualan dan pemasaran. Pada UD Adan UD. B terdapat fungsi bisnis pengadaan, produksi, Logistik Outbond dan penjualan dan pemasaran.

2. Value driver dari UD. $X$ dan UD $Y$ adalah kualitas produk dan efisiensi waktu produksi.

3. Manfaat ekonomi standar Pada UD. X sebesar Rp32.322.370,00 danpada UD. Y Rp34.302.107,00

4. Perkiraan proyeksi yang akan didapatoleh UD. Adan UD B dapat dilihat dari segi kuantitatif dan kualitatif. Dari segi kualitatif manfaat yang akan di terima adalah sebagai berikut.

- Transfer informasi lebih baik

- adanya evaluasi pegawai dan kinerja

- adanya perubahan aktivitas kebutuhan bahan baku

- adanya pemilihan supplier

- adanya peningkatan kualitas fasilitas produksi

- adanya penjaminan pengiriman

- Tingkat penjualan yang meningkat.

Berikut adalah proyeksi manfaat penerapan SNI yang akan didapat oleh UD, A dan UD. B. Manfaat yang didapat dari UD. X didapatkan sebesar Rp32.322.370,00 menurut UD. X dan UD. Y sebesar Rp34.302.107,00 .
Terimakasih kepada Departemen Teknik Industri, UD. Y, UD. X, UD. Adan UD. B, dan seluruh pihak yang terkait dalam membantu penyelesaian penelitian ini.

\section{DAFTAR PUSTAKA}

Alfonso Rodríguez-Escobar, J., Gonzalez-Benito, J., \& Rafael Martínez-Lorente, A. (2006). An analysis of the degree of small companies' dissatisfaction with ISO 9000 certification. Total Quality Management and Business Excellence, 17(04), 507521.

http://doi.org/10.1080/14783360500528 304

Biatna Dulbert., \& BSN. (2014). Kajian Awal Dampak Ekonomis Penerapan SNI Pada Produk Prioritas Terhadap Ekonomi Nasional. Jakarta: Badan Standardisasi Nasional, Jakarta.

Danar A. Susanto, Isharyadi, F \& Ritonga, M. (2017). Manfaat Ekonomi Penerapan Standar pada Usaha Kecil Menengah Menggunakan ISO Methodology. Jurnal Standardisasi, 17(1), 25-38.

Farkah, S. (2011). Penilaian Manfaat Ekonomi Dari Penerapan Standard Dengan Metodologi ISO (Studi Kasus Unit Bisnis Spinning PT Apac Inti Corpora Semarang). (Doctoral dissertation, Dipenogoro University). Retrieved from http://eprints.undip.ac.id/32896/

International Organization for Standardization. (2010). Economic Benefits of Standards - ISO Methodology 1.0. Geneva. Retrieved from http://www.iso.org/iso/home/store/public ation_item.htm?pid=PUB100288 
International Organization for Standardization.

(2013). Economic Benefits of Standards

- ISO Methodology 2.0. Geneva: ISO.

Retrieved

from

http://www.iso.org/iso/pub100344.pdf

Karipidis, P., Athanassiadis, K., Aggelopoulos, S., \& Giompliakis, E. (2009). Factors affecting the adoption of quality assurance systems in small food enterprises. Food Control, 20(2), 93-98. http://doi.org/10.1016/j.foodcont.2008.02 .008

Mulyono, A. B., \&Pudjiastuti, U. (2013). Manfaat Ekonomi Penerapan Standar di Sektor Makanan Menggunakan Metodologi ISO. Jurnal Standardisasi.15(1), 66-81.

Porter, M.E. (1985). Competitive Advantage Creating and Sustaining Superior Performance. The Free Press, New York

Poksinska, B., Eklund, J. A. E., \& Jörn Dahlgaard, J. (2006). ISO 9001:2000 in small organisations. International Journal of Quality and Reliability Management. 23(5), 490-512.

Ulkhaq, M. W. (2010). Penilaian Manfaat Ekonomi Dari Penerapan Standar Dengan Metodologi ISO Studi Kasus PT. ISTW Semarang Tahun 2010 (Doctoral dissertation, Dipenogoro University). Semarang. Retrieved from http://eprints.undip.ac.id/30041/

Sari, R. (2012). Penilaian Manfaat Ekonomi Penerapan Stadar Dengan Metodologi ISO Studi Kasus PT. Kubota Indonesia. (Doctoral dissertation, Dipenogoro University). Semarang. Retrieved from http://eprints.undip.ac.id/32748/ 
Prosiding PPIS 2019 - Semarang, 11 Oktober 2019, Hal 323-332 